\title{
Acoustical and Vibrometry Analysis of a Large Balinese Gamelan Gong
}

\author{
by \\ David W. Krueger
}

A Physics 492R Capstone Project Report

Advisor: Kent L. Gee

Department of Physics and Astronomy

Brigham Young University

July 2009 


\begin{abstract}
A large Balinese gamelan gong, the gong ageng wadon, is similar to other Indonesian gongs in that it is tonal. A previously undocumented phenomenon is the distinct acoustic beating this gong produces. In this study of the Brigham Young University's gong ageng wadon, acoustical and vibrometry measurements were performed. Scanning laser Doppler vibrometer results show a beat frequency of about $3 \mathrm{~Hz}$ is produced near $150 \mathrm{~Hz}$ and $160 \mathrm{~Hz}$ by closely spaced structural modes. A slightly slower beat frequency (around $2.5 \mathrm{~Hz}$ ) is also produced at about $120 \mathrm{~Hz}$. The difference in this case is that there is only one structural mode measured near this frequency. The acoustic radiation from this mode beats with a harmonic of the radiation from a lower structural mode, which harmonic is caused by nonlinear structural phenomena.
\end{abstract}

\title{
Introduction
}

In Indonesia, a gamelan, a generic term that means “orchestra,” consists of a variety of percussive instruments such as metallophones, chimes, xylophones, drums, and gongs. The size of a gamelan can range from a few instruments to over seventy-five. In Balinese gamelan, metallophones are manufactured in pairs, with the female instruments' bars tuned slightly lower in frequency than their male counterparts. This purposeful tuning of a pair to slightly different frequencies results in acoustic beating as they are struck in unison, which is referred to in Bali as “ombak” (meaning “wave”). The beating or ombak results in a shimmering quality to the music that is unique to Bali. For a general understanding of gamelan, the reader is referred to Ref. 1.

Some instruments in the ensemble do not need to be played in unison with another instrument for beating to occur. For example, the gong ageng wadon, which is the largest gong in the gamelan, produces a tonal sound with beating of about $2.5 \mathrm{~Hz}$ when struck with a padded mallet. Rossing and Shepherd ${ }^{1}$ found that the tonality of the gong can be attributed to the raised 
dome in the center (referred to as the boss), where the gong is struck. The mass and size of the boss relative to the rest of the gong causes a nearly two to one relationship of the two principal axisymmetric modes of vibration, giving the gong its tonality. Current literature does not, however, explain which modes are responsible for the gong's ombak.

In this Letter, we describe essential features of the modal response of the gong ageng wadon and the origin of its ombak. In a sense, the Letter proceeds chronologically as we describe initial structural and acoustical measurements that only partially revealed the origin of the ombak. These measurements motivated a deeper experimental investigation. In the process, we learned that the dominant perceived ombak is created by a nonlinear structural response of the gong's lowest axisymmetric mode interacting with the nearly harmonic second axisymmetric mode. Other ombak present is created by closely spaced structural modes that appear to be purposefully hammered into the gong's response.

\section{Initial Acoustical and Structural Measurements}

To determine the frequencies present in the gong's response, acoustical measurements on the gong were taken in a large room, roughly $74.3 \mathrm{~m}^{2}\left(800 \mathrm{ft}^{2}\right)$, with no sizeable obstructions within approximately $2.5 \mathrm{~m}(8 \mathrm{ft})$ of the gong. Three types of sensors were used for the tests. One was a 12.7-mm (0.5 in) GRAS Type-1 microphone placed behind the gong and within the cavity. In all tests, the microphone was placed in the same location relative to the gong. Another sensor was a PCB accelerometer placed on the front of the gong directly on top of the boss. The third sensor used was a Polytec scanning laser Doppler vibrometer (SLDV) used to take noncontact measurements of the vibration of the gong. The microphone and accelerometer data were acquired with a National Instruments USB-9233 16-bit data acquisition module with a sampling rate of $50 \mathrm{kHz}$. 

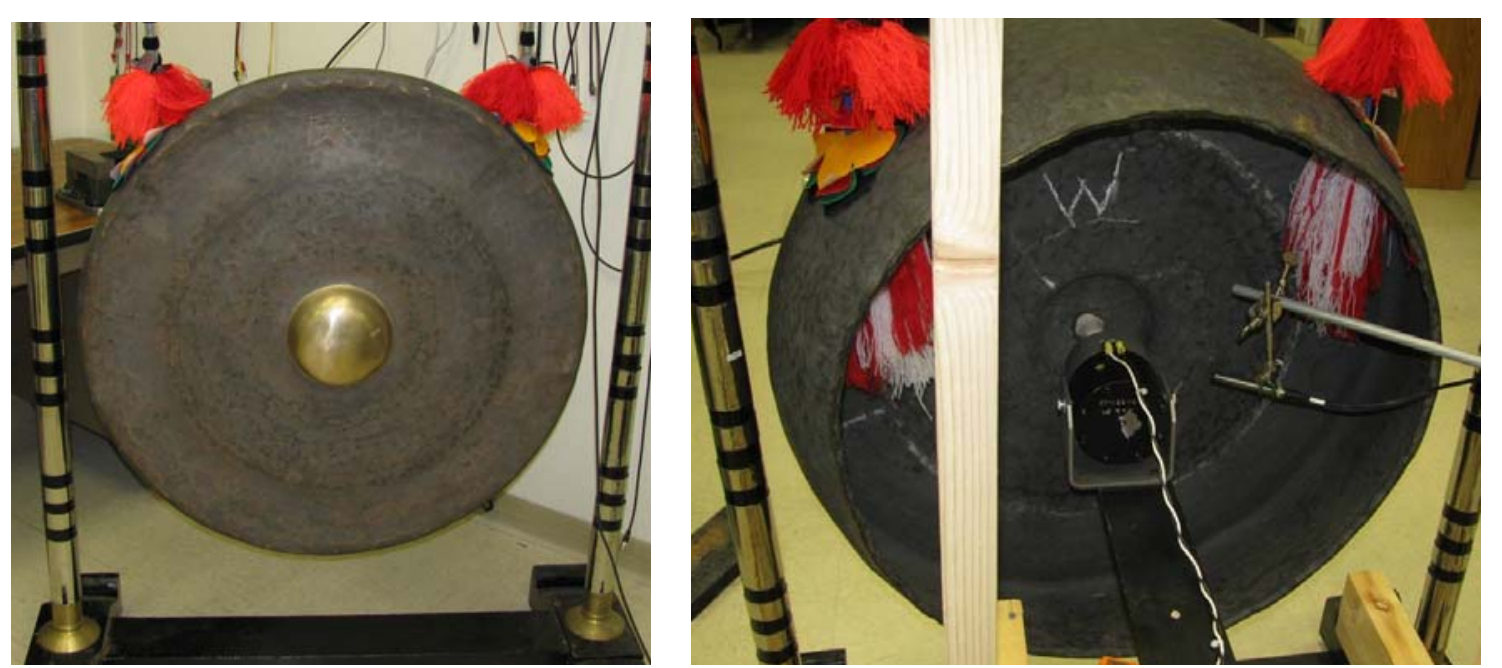

Figure 1: Left: The front of the gong, with the boss (the polished, raised dome at the center) visible. Right: Microphone placement behind the gong and the location of a shaker that was used for some tests to drive the gong continuously.

Figure 2a shows the acoustic pressure spectrum calculated from the recording, in relative decibels, when the gong is struck. Note that the high quality factor peaks suggests that the modes of vibration of the gong are very stable as they decay. There are several natural frequencies, given in Table 1, that have a neighbor within a few hertz of one another and others that do not. In examining the spectrogram of the same recording in Fig. 2b, these pairs of natural frequencies result in ombak except at the pair near $60 \mathrm{~Hz}$, which has too great an amplitude difference. The ombak near $120 \mathrm{~Hz}$ and $180 \mathrm{~Hz}$ has a beat frequency of about $2.5 \mathrm{~Hz}$. The spacings of the paired modes at about 150 and $160 \mathrm{~Hz}$ suggests beating from 3-13 Hz, which when coupled with the 6-Hz frequency resolution in the spectrogram, yields a complicated temporal response. It is also noteworthy that the $120-\mathrm{Hz}$ and $180-\mathrm{Hz}$ ombak appear to be in phase. 

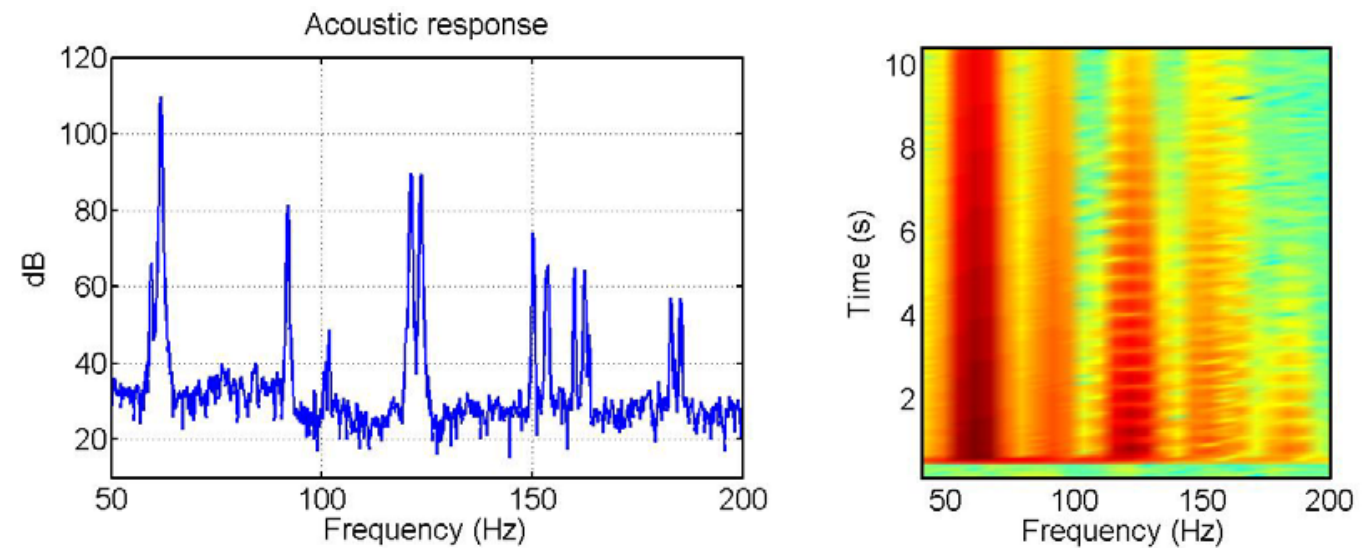

Figure 2: Acoustic spectrum and spectrogram when the gong is stuck with a padded mallet.

Initial structural measurements of the face of the gong were made using a Polytec SLDV.

The gong was excited with white noise from a Mackie HR624 loudspeaker placed near the rear cavity of the gong. Figure 3 shows all of the modes measured by the SLDV below $240 \mathrm{~Hz}$, among which are two axisymmetric modes that occur at 61.75 and $121.25 \mathrm{~Hz}$. This is the nearly 2:1 ratio that, as explained by Rossing and Shepherd, ${ }^{1}$ causes the gong to be tonal. Notice that both axisymmetric modes have an antinode on the boss, while the other modes do not, which produces greater average displacements and relatively large acoustic amplitudes. The frequencies of the SLDV-measured modes in Fig. 3 are also provided in Fig. 3.

In Fig. 3, note that most of the modal shapes shown are characteristic of circular geometry of the gong. The exceptions are the pairs near150 and $160 \mathrm{~Hz}$, which are quite asymmetric and appear to be phase-shifted versions of one another. This phenomenon appears to be related to the work of Chaigne et al., ${ }^{2}$ who studied vibrations of shallow spherical shells and gongs. They described how asymmetric modes (ones without nodal diameters) occur in pairs that have the same pattern but are phase shifted by $90^{\circ}$. Gong inhomogeneities break up the mathematical degeneracy that would normally be expected for these asymmetric modes. We found this $90^{\circ}$-phase shift degeneracy also occurs between the 92 and $101.75 \mathrm{~Hz}$ modes, which have the nodal diameters. 

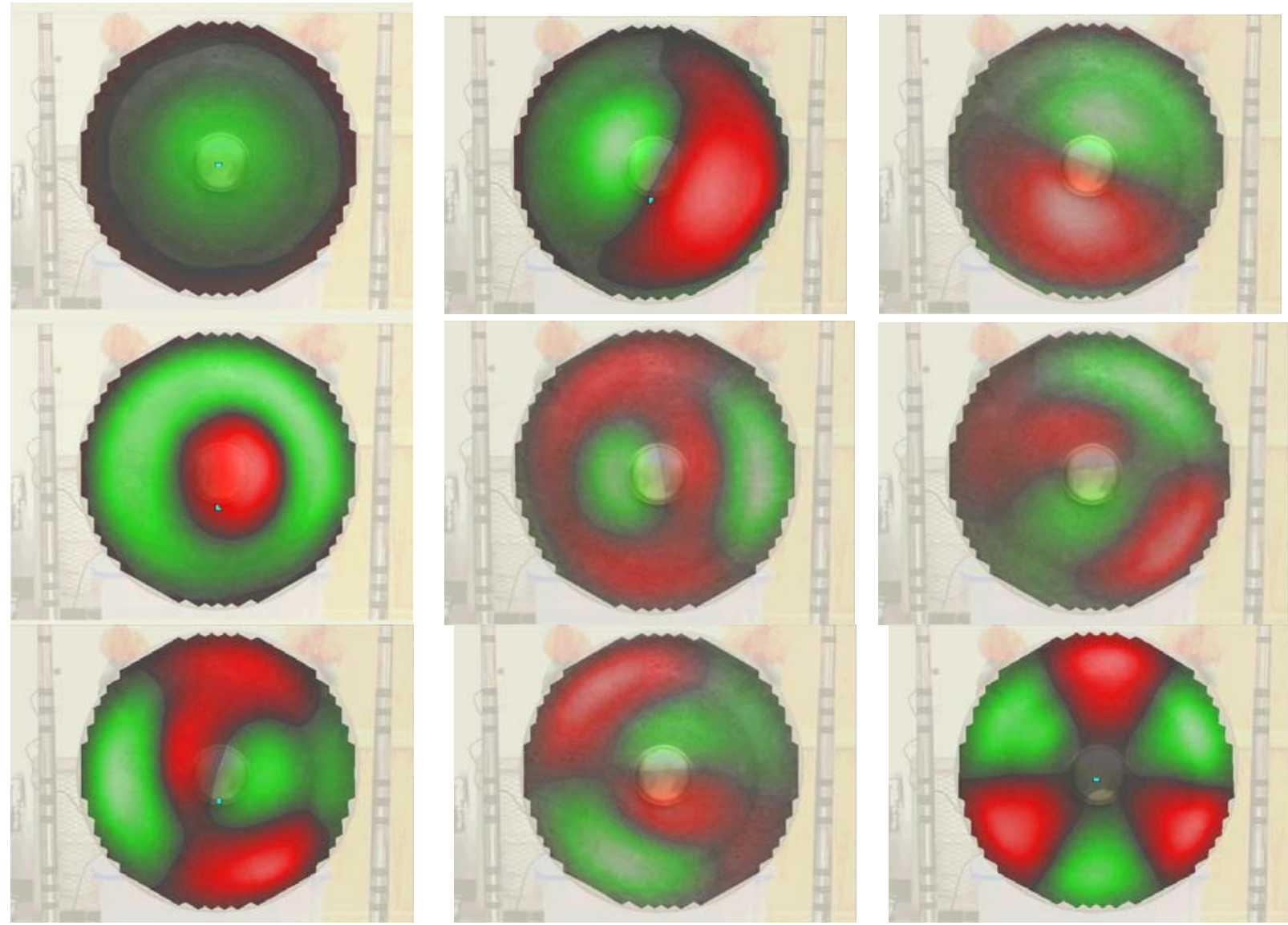

Figure 3: SLDV screenshots of vibrational modes at (Top L-R): 61.75, 92.0, 101.75 Hz; (Middle L-R): 121.25, 150.25, 153.25 Hz; (Bottom L-R): 160, 162.5, 236 Hz.

The results in Fig. 3 represent a partial solution to the origin of the ombak. The beating around $150-160 \mathrm{~Hz}$ is caused by asymmetric structural modes that are sufficiently close in amplitude and frequency. Their asymmetry, amplitudes, and frequencies suggest that these modes were deliberately hammered into the response of the gong to produce ombak.

A comparison between the acoustically and structurally measured natural frequencies in Table 1 immediately reveals a discrepancy between the two responses. One would expect all the frequencies present acoustically to be present structurally. However, this is not the case. For example, there is an acoustic response at $123.5 \mathrm{~Hz}$ as well as a pair of peaks near $180 \mathrm{~Hz}$ that do not show up structurally.

The fact that the acoustic spectral response of the gong when struck has frequencies present that are not part of the structural response of the gong when excited acoustically with 
broadband noise suggests a nonlinear response of the gong not captured by the SLDV

measurement. Upon examination of the natural frequencies, we noted that there is an exact linear relationship between the lowest two axisymmetric modes $(61.75 \mathrm{~Hz}$ and $121.25 \mathrm{~Hz})$ and all the peaks that are present in the acoustic but not in the SLDV data. This relationship is also shown in Table 1. These missing frequencies in the SLDV-measured structural response are essential to the gong's ombak because the 120 and $180-\mathrm{Hz}$ in-phase beating occurs at these frequencies. Further measurements to characterize the nonlinear response of the gong are now described.

Table 1: Peak frequencies of the structural and acoustic responses measured by the SLDV and microphone; Also, peaks present acoustically but not structurally have a harmonic relationship with two structural peaks, 61.75 and $121.25 \mathrm{~Hz}$ (called $\mathrm{f}_{1}$ and $\mathrm{f}_{2}$, resp., in the table).

\begin{tabular}{|c|c|c|c|c|c|c|c|c|c|c|c|c|}
\hline SLDV (Hz) & - & 61.75 & 92 & 101 & 121.25 & - & 150.25 & 153.25 & 160 & 162.5 & - & - \\
\hline Mic (Hz) & 59.5 & 61.75 & 92 & 101 & 121.25 & 123.5 & 150.25 & 153.25 & 160 & 162.5 & 183 & 185.25 \\
\hline Relationship & $f_{2}-f_{1}$ & & & & & $2 f_{1}$ & & & & & $f_{1}+f_{2}$ & $3 f_{1}$ \\
\hline
\end{tabular}

\section{Investigation of Gong's Nonlinear Response}

To further investigate the modal frequencies absent from the SLDV measurement in Table 1, a Labworks Inc. ET-126B shaker was attached to the back of the gong (see Fig. 1). The shaker permitted steady-state gong excitation at greater amplitudes than was possible via acoustic excitation. This is similar to a technique used by Chaigne. ${ }^{3}$ The input to the shaker was a summation of $61.75 \mathrm{~Hz}$ and $121.25 \mathrm{~Hz}$ sine waves. The boss-mounted accelerometer and the microphone were used to determine the structural and acoustic responses of the gong. It was quickly discovered that although the gong was mechanically being driven at only these two frequencies, we were measuring both acoustically and structurally additional frequencies that corresponded exactly to the peaks missing from the structural response. The amplitudes of the two tones were adjusted such that the relative acoustic amplitudes of the two modes matched those of the struck gong, which caused distinct beating to occur. 
With the ombak quite audible, the voltage of the $61.75 \mathrm{~Hz}$ tone to the shaker was nearly 5 times that of the $121.25 \mathrm{~Hz}$ tone. Figure 4 shows the acoustic spectrum and spectrogram of this steady-state beating. Both $61.75 \mathrm{~Hz}$ and $121.25 \mathrm{~Hz}$ are present as are their sum and difference frequencies. These sum and difference frequencies are the missing frequencies from the structural response discussed in the previous section.
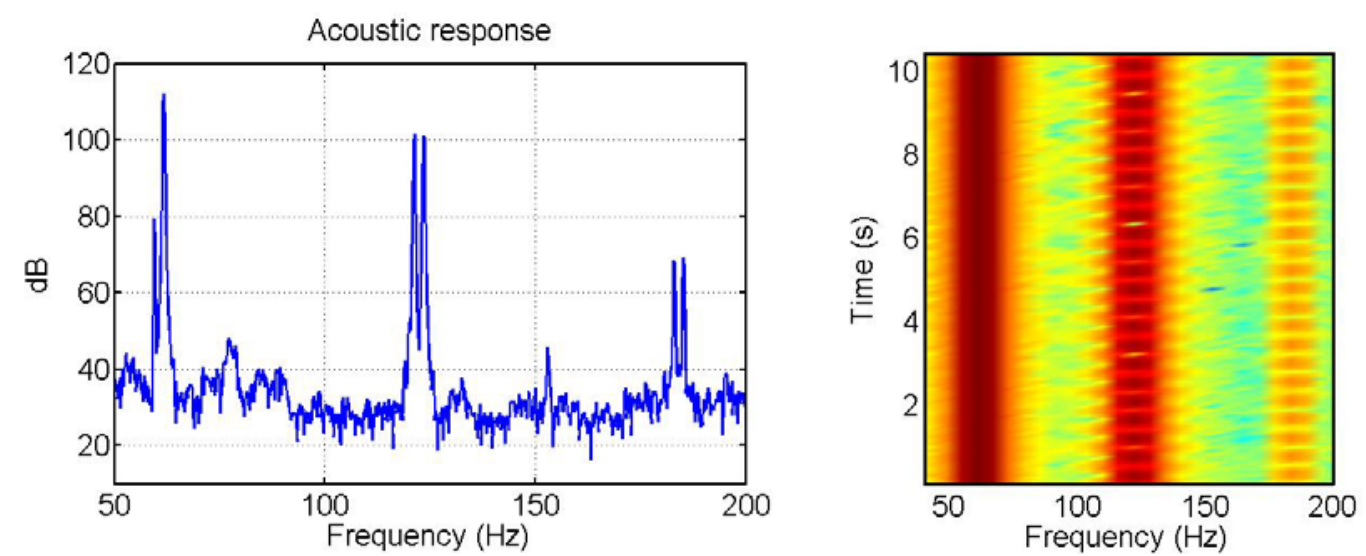

Figure 4: Acoustic spectrum and spectrogram when the gong is driven by a shaker at $61.75 \mathrm{~Hz}$ and 121.25 $\mathrm{Hz}$, simultaneously.

The results shown previously demonstrate that the gong is responding in a quadratically nonlinear fashion. The nonlinear response appears to be mostly limited to the $61.75-\mathrm{Hz}$ mode interacting with itself to produce harmonics and with the $121.25 \mathrm{~Hz}$ mode to produce sum and difference frequencies. To confirm the nonlinear response of the gong is structural and not acoustic in nature, the shaker was driven with a $61.75 \mathrm{~Hz}$ tone at different voltages. Figure 5 shows the measured relative pressure and acceleration levels as a function of output voltage from the signal generator. The solid arrow shows the slope of the increase of the fundamental mode. The dash arrow and the dash dot arrow show the increase of the second and third harmonics, respectively. The greater rate of increase of the harmonics' amplitudes relative to the increase of the fundamental verifies that indeed the gong is responding nonlinearly. The equal slopes of the microphone and accelerometer level increases confirm that the acoustic response is a linear function of the nonlinear response of the gong. 
Previous studies characterizing the nonlinear behavior of gongs have focused mainly on the Chinese tam-tam. ${ }^{4,5,6}$ The nonlinearity is described in terms of nonlinear mode coupling, which produces new modes at harmonics of ordinary modes, a chaotic response, and drift of modal frequencies as a function of strike amplitude. We have shown the nonlinear mode coupling does exist in the gong ageng wadon, which is the dominant cause of its ombak, but the nonlinear response in this current study is different from the tam-tam in that a) it is not chaotic and b) the modal frequency does not appear to change with amplitude. There is a point at which an exceedingly hard strike with the padded mallet causes a chaotic response of the gong ageng wadon, but that point is well beyond normal performance conditions.

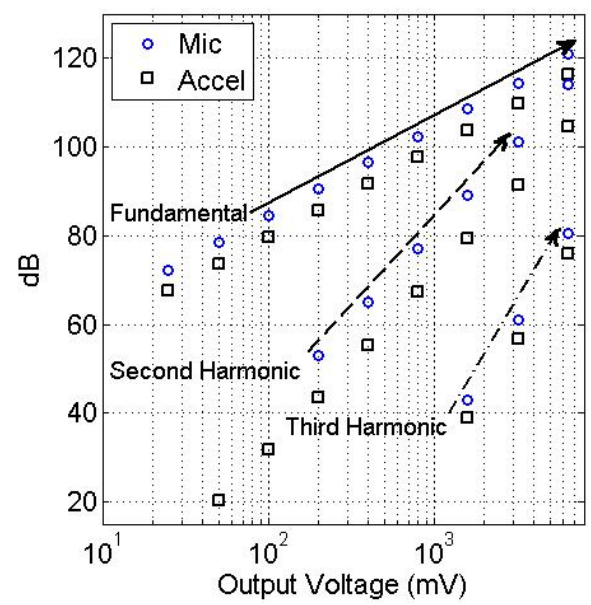

Figure 5: Comparison of the growth of the second and third harmonic (dashed and dash dotted arrows) relative to the growth of the fundamental $(61.75 \mathrm{~Hz}$, solid arrow) as output voltage from the signal generator is increased.

\section{Conclusions}

This investigation has revealed two sources of ombak in the gong ageng wadon. First, there appear to be structural modes that have been specifically created in the gong's response due to their asymmetric shapes not expected in the response of a circular gong face. These modes are part of the gong's linear response, contribute to the timbre and "shimmer" of the gong's response, but are not the dominant source of ombak in the gong. The dominant ombak is caused 
by the nonlinearly-generated second harmonic of the fundamental axisymmetric mode interacting with the quasiharmonic second axisymmetric mode. This phenomenon was not observed when exciting the gong acoustically, but was readily observable when the gong was driven by a shaker at the frequencies of the first two axisymmetric modes at amplitudes comparable to when the gong is struck.

The results of this investigation into the origin of ombak in the gong ageng wadon are particularly fascinating given the intuitive, artistic process that is the creation of these large gongs. The gong ageng wadon of the BYU gamelan was forged in Java from a bronze alloy. ${ }^{7}$ For hundreds of years, the gong smiths have altered the shape and size of the boss to produce a very tonal sound that is unique among gongs. Furthermore, their adjustment of structural modes in the tuning process so that they are both close in frequency and amplitude is unexpected because of its circular geometry. Finally, that the dominant ombak relies on a nonlinear response of the gong and that the relative amplitudes of the fundamental and second axisymmetric modes must be such that the nonlinearly-generated second harmonic of the fundamental and the second axisymmetric modes' amplitudes are approximately equal is remarkable. Future studies of gamelan gongs may focus on the comparative behavior of the smaller gongs, some of which are designed to not produce ombak. In addition, the directivity of the gongs' acoustic radiation may be studied as well.

\section{References:}

${ }^{1}$ T. D. Rossing, and R. B. Shepherd, (1982). Acoustics of gamelan instruments. Percussive Notes 19 (3), 73-83.

${ }^{2} \mathrm{~A}$. Chaigne, et. al., "Vibrations of shallow spherical shells and gongs: a comparative study," Forum Acusticum, 1-6 (2002).

${ }^{3}$ A. Chaigne, C. Touzé, and O. Thomas, "Nonlinear vibrations and chaos in gongs and cymbals," Acoust. Sci. \& Tech. 26, 5 (2005).

${ }^{4}$ N. H. Fletcher, and T. D. Rossing, The Physics of Musical Instruments, (Springer-Verlag New 
York Inc., 1991), pp. 555-566.

${ }^{5}$ N. H. Fletcher, “The nonlinear physics of musical instruments,” Rep. Prog. Phys. 62 (1999) 758-760.

${ }^{6}$ K. A. Legge, and N. H. Fletcher, "Nonlinearity, chaos, and the sound of shallow gongs,” J. Acoust. Soc. Am. 86(6) 2439-2443 (1989).

${ }^{7}$ L. Gold, Music in Bali: Experiencing Music Expressing Culture, (New York and Oxford Univ. Press) (2005) 31.

\section{Acknowledgments:}

Kent L. Gee, Dept. of Physics and Astronomy, Brigham Young Univ.

Jeremy Grimshaw, School of Music, Brigham Young Univ.

Molly E. Jones, Univ. of Michigan

Dorothy Manuel, Spelman College

Daniel Manwill, Brigham Young Univ.

Work supported by The Department of Physics and Astronomy, Brigham Young Univ. 